\title{
Resuscitation of preterm babies at birth reduces the risk of death from hyaline membrane disease
}

\author{
EVELYN ROBSON AND EDMUND HEY \\ Princess Mary Maternity Hospital, Newcastle upon Tyne
}

SUMMARY Increased attention to pulmonary aeration and oxygenation by early recourse to active resuscitation at birth was associated with a $20 \%$ reduction in mortality from hyaline membrane disease in preterm babies of 1-2 kg in 1971-76 compared with 1960-67. There were no other identifiable changes in management during this period.

Babies of 1-2 kg born at this hospital between 1960 and 1967 who were pink on admission to the special care nursery at birth were only one-quarter as likely to die of hyaline membrane disease as those who were cyanosed on admission. Omer et al. ${ }^{1}$ in presenting these findings were drawn to ask the question, 'Can initial resuscitation of preterm babies reduce the death rate from hyaline membrane disease?'. They therefore adopted a policy of early intervention with elective intubation and ventilation at birth for all but the most vigorous preterm babies. Careful attention to adequate oxygenation and warmth was maintained during transfer and stabilisation in the nursery, using an in-dwelling orotracheal tube if necessary. This new policy caused a 3-fold reduction in the number of preterm babies who were cyanosed on admission and reduced the number of deaths from hyaline membrane disease, but the reduction failed to reach statistical significance during the period of study (1971-72) because there were too few infants. ${ }^{1}$

We have now reviewed the evidence afresh for the period since 1971 and report the final outcome of the study originally initiated by Neligan and Robson 10 years ago. A policy of minimum handling ${ }^{2}$ was maintained, radiological investigation was kept to a minimum, and oral feeding started only if it could be established that the baby had no sign of respiratory distress. In these and other respects management remained unaltered. Hand ventilation (with unhumidified oxygen) at a peak inspiratory pressure of $3 \mathrm{kPa}\left(30 \mathrm{cmH}_{2} \mathrm{O}\right)$ was however, always used in every intubated baby to combat any increased resistance to airflow during this period of early stabilisation.

\section{Results}

Between 1960 and 1967 the proportion of hospital- born babies dying each year from hyaline membrane disease remained consistent at $10 \cdot 77 \pm 0.33 \%$ (mean \pm SEM) of all 1-2 kg livebirths. ${ }^{1}$ Comparable figures for the period 1971-79 showed a total of 430 births weighing 1-2 kg. All but 2 of the nonmalformed babies to die had necropsy examinations. Only $30(6.9 \%)$ of the babies died with hyaline membrane disease. Management remained unaltered until 1977 when a policy of early recourse to ventilatory support was introduced for babies with severe respiratory acidosis or frank cyanosis in high concentrations of oxygen. This reduced the overall mortality but caused a substantially greater increase in the number of babies receiving ventilatory support, rendering comparison with the period 1960-67 difficult. For this reason we have limited this present review to the years 1971-76.

Between 1971 and 1976 there were 264 babies de ivered in the hospital weighing 1-2 kg and only 14 of them were blue on admission to the nursery. Nineteen babies died of hyaline membrane disease with or without intraventricular haemorrhage and a fur her 4 survived only after a period of prolonged artificial ventilation (Table)

The number of babies who died each year (or survived only after prolonged ventilation) was very similar each year (mean $8 \cdot 79 \pm 0 \cdot 20 \%$ ). Mortality therefore fell by more than one-fifth $(P<0.001)$ when greater attention was pa $d$ to resuscitation at birth. Management remained constant in all other respects between 1960 and 1976 apart from the introduction of artificial ventilation using a Bennett PR2 ventilator in 1968 for babies with signs of terminal respiratory failure.

Twenty-seven per cent of the babies were judged to be asphyxiated at delivery inciuding 15 of the babies who died (or survived only after artificial ventilation) between 1971 and 1976. Seventy-four per cent were 
Table Death from hyaline membrane disease in babies of 1.0 to $2.0 \mathrm{~kg}$ at birth

\begin{tabular}{|c|c|c|c|c|}
\hline Years & $\begin{array}{l}\text { Condition on } \\
\text { admission }\end{array}$ & $\begin{array}{l}\text { Number } \\
\text { of babies }\end{array}$ & $\begin{array}{l}\text { Deaths } \\
\text { from } H M D^{*}\end{array}$ & $\begin{array}{l}\text { HMD death } \\
\text { rate }(\%)\end{array}$ \\
\hline $1960-67$ & $\begin{array}{l}\text { Pink } \\
\text { Blue }\end{array}$ & $\begin{array}{r}382 \\
83\end{array}$ & $\begin{array}{l}26 \\
24\end{array}$ & $\left.\begin{array}{r}6.8 \\
28.9\end{array}\right\} 10.7$ \\
\hline $1971-76$ & $\begin{array}{l}\text { Pink } \\
\text { Blue }\end{array}$ & $\begin{array}{r}250 \\
14\end{array}$ & $\begin{array}{r}18 \\
5\end{array}$ & $\left.\begin{array}{r}7 \cdot 2 \\
35 \cdot 7\end{array}\right\}$ \\
\hline
\end{tabular}

HMD = hyaline membrane disease.

* Four babies survived after prolonged ventilation for HMD between 1971 and 1976 (one of whom was cyanosed on admission); they have been classified as 'deaths' for the purpose of the present analysis to make the two study periods comparable because effective equipment for providing artificial ventilation only became available in 1968 .

given oxygen by intermittent positive pressure at birth in the second 6-year period compared with $38 \%$ in the first 8 -year period. The birthweight distribution remained unchanged.

\section{Discussion}

There are difficulties in comparing the outcome of management in the early 1960 s with management in the early 1970s, but there were few changes in the policy for managing hyaline membrane disease between 1960 and 1976. The same senior medical and nursing staff were in charge throughout, and no attempt was made to introduce the newer techniques of antepartum beclomethasone prophylaxis, antepartum fetal blood gas monitoring, intra-arterial neonatal blood gas and blood pressure monitoring after del'very, or cons'ant positive airways pressure treatment when these were first widely popularised in the early 1970 s. There was no change in the incidence of proved or suspected sepsis or pneumonia during the period covered by the survey and no change in the very small number given antibiotic treatment. Feeding policy also remained unchanged, although there was a marginal increase in intravenous fluid intake in babies aged more than 48 hours during the latter part of the study. Rather fewer babies were hypothermic on admission after 1970 , but there were no differences in subsequent mean rectal temperature; neither was there any correlation between body temperature on admission and final outcome (after allowing for the strong correlation between birthweight, initial asphyxia, and outcome). It is however, impossible to rule out some subtle but important change in management during a 17-year period.

Nevertheless, although the overall prognosis for babies of 1-2 kg improved significantly during that time, the improvement was entirely due to the abrupt decrease in the number of deaths from hyaline membrane disease, and was only of the magnitude predicted by the 3-fold decrease in the number of cyanosed babies admitted to the nursery after birth (if allowance is made for the 4 babies who survived only after prolonged artificial ventilation between 1970 and 1976). The prognosis for bab es who were pink on admission remained 4 times as good as the prognosis for cyanosed babies, and did not improve between 1960 and 1976.

Lung function is now known to be abnormal even at birth $^{3}$ in many babies who eventually die of hyaline membrane disease, and the poor prognosis of those babies with cyanosis on admission could be merely an expression of the functional immaturity of the baby's lung. However, the reduced incidence of cyanosis and decreased mortality in those babies subjected to more careful resuscitation indicates that greater attention to establishing effective aeration of the lung at birth can decrease the risk of lethal hyaline membrane disease as Omer et al. ${ }^{1}$ suspected. Attention was focused initially on the importance of avoiding hypothermia or cyanosis after delivery, but later attention was also focused on improving the even aeration of the lung, encouraging the development of a stable functional residual capacity, and correcting any possible acidosis with a period of elective hyperventilation after delivery. The theoretical risks of hypothermia and acidosis are apparent from the evidence of Gluck et al. ${ }^{4}$ who found that such insults had a profound and immediate effect on surfactant production, ${ }^{5}$ and several controlled trials have shown the value of correcting any acidosis detected shortly after birth. ${ }^{6}$ There are however potential hazards in using sodium bicarbonate for this purpose, and good reasons for considering artificial hyperventilation a safer and more 'physiological' means of achieving the same objective. Pure oxygen was used partly as a matter of convenience, but also because there is some evidence that its use improves effective pulmonary blood flow 78 and no evidence that a short period of hyperoxia is dangerous. Babies with hyaline membrane disease are known to expand their lungs poorly at birth ${ }^{39}$ and atelectasis is clearly capable of setting in train many of the self-perpetuating problems associated with the disease process. This therefore, provided another potential reason for undertaking elective resuscitation at birth.

It is $\mathbf{1 5}$ years since experimental fetal distress was first clearly shown to augment the risk of respiratory distress and hyaline membrane formation in the immature lamb. ${ }^{10}$ In human infants, the risk of respiratory distress in the second twin is known to be 3 times as high as in the first twin, ${ }^{11}$ and the risk of death from hyaline membrane disease nearly doubles $^{12}$ when at least one infant is affected at birth. Different rates of surfactant maturation have 
occasionally been documented in multiple pregnancy, ${ }^{13}$ but different degrees of intrapartum asphyxia are a more likely explanation for the differing outcome. While many preterm babies develop respiratory distress even in the absence of acidosis at birth, ${ }^{6}$ infants with acidosis and cardiotochographic evidence of fetal distress during labour are known to have an increased incidence of respiratory distress, ${ }^{14}$ and an increased risk of death from hyaline membrane disease. ${ }^{15}$

These data suggest that adequate resuscitation at birth and the careful avoidance of all asphyxial stress after delivery did more to reduce mortality from hyaline membrane disease in Newcastle between 1971 and 1976 than the provision of artificial respiratory support for babies with established disease: that prevention is quicker than cure. It also appeared to work better than prolonged artificial ventilation during the years covered by this study although with recent improvements in technique this is probably no longer true. Nevertheless, if attention to treating asphyxia in the preterm infant immediately after birth can reduce mortality from hyaline membrane disease by one-fifth, it is likely that even more could be achieved by increased attention to asphyxia before delivery.

We are indebted to the late $\operatorname{Dr}$ G A Neligan whose consistent and dedicated care and deep interest in all aspects of basic nursing management made this study possible. His collaborative research with E R covered a period of over twenty years and we regret that he did not live long enough to write this paper himself.

We thank the members of the staff of the Department of Pathology who provided necropsy reports and helped with the final histological reviews.

\section{References}

1 Omer M I A, Robson E, Neligan G A. Can initial resuscitation of preterm babies reduce the death rate from hyaline membrane disease? Arch Dis Child 1974; 49: 219-21.

2 Speidel B D. Adverse effects of routine procedures on preterm infants. Lancet 1978; i: 864-6.
3 Hey E, Hull D. Lung function at birth in babies developing respiratory distress. $J$ Obstet Gynaecol $\mathrm{Br}$ Commonw 1971; 78: 1137-46.

4 Gluck L, Kulovich M V, Eidelman A I, Cordero L, Khazin A F. Biochemical development of surface activity in mammalian lung. IV. Pulmonary lecithin synthesis in the human fetus and newborn and etiology of the respiratory distress syndrome. Pediatr Res 1972; 6: 81-99.

5 Merritt T A, Farrell P M. Diminished pulmonary lecithin synthesis in acidosis: experimental findings as related to the respiratory distress syndrome. Pediatrics 1976; 57: 32-40.

6 Kenny J D, Adams J M, Corbet A J S, Rudolph A J. The role of acidosis at birth in the development of hyaline membrane disease. Pediatrics 1976; 58: 184-91.

7 Sinclair J C, Engel K, Silverman W A. Early correction of hypoxemia and acidemia in infants of low birth weight: a controlled trial of oxygen breathing, rapid alkali infusion, and assisted ventilation. Pediatrics 1968; 42: 565-89.

8 Hansen T N, Corbet A J S, Kenny J D, Courtney J D, Rudolph A J. Effects of oxygen and constant positive pressure breathing on aADCO ${ }_{2}$ in hyaline membrane disease. Pediatr Res 1979; 13: 1167-71.

9 Boughton K, Gandy G, Gairdner D. Hyaline membrane disease. II. Lung lecithin. Arch Dis Child 1970; 45: 311-20.

10 Reynolds E O R, Jacobson H N, Motoyama E K, et al. The effect of immaturity and prenatal asphyxia on the lungs and pulmonary function of newborn lambs: the experimental production of respiratory distress. Pediatrics $1965 ; 35$ : 382-92.

11 Neligan G A, Robson E, Hey E N. Letter: Hyaline membrane disease in twins. Pediatrics 1969; 43 : 143.

12 Rokos J, Vaeusorn O, Nachman R, Avery M E. Hyaline membrane disease in twins. Pediatrics $1968 ; 42$ : 204-5.

13 Weller P H, Jenkins P A, Gupta J, Baum J D. Pharyngeal lecithin/sphingomyelin ratios in newborn infants. Lancet 1976; i: $12-5$.

14 Hobel C J, Hyvarinen M A, Oh W. Abnormal fetal heart rate patterns and fetal acid-base balance in low birthweight infants in relation to respiratory distress syndrome. Obstet Gynecol 1972; 39: 83-8.

15 Martin C B, Siassi B, Hon E H. Fetal heart rate patterns and neonatal death in low birthweight infants. Obstet Gynecol 1974; 44: 503-10.

Correspondence to Sister E Robson, Child Health Unit, Princess Mary Maternity Hospital, Great North Road, Newcastle upon Tyne NE2 3BD.

Reprints will not be available.

Received 28 April 1981 